\title{
Cadaveric Measurements of the Left Recurrent Laryngeal Nerve, Ligamentum Arteriosum, Aortic Arch, and Pulmonary Artery in the Thorax with Clinical Implications and Comparison Between Two Sexes in the American Population
}

\author{
Anasuya Ghosh ${ }^{1}$, Subhramoy Chaudhury ${ }^{1}$ \\ 1. Anatomy, Medical University of the Americas, Charlestown, KNA
}

$\square$ Corresponding author: Subhramoy Chaudhury, subhramoychaudhury@gmail.com Disclosures can be found in Additional Information at the end of the article

\section{Abstract}

The left recurrent laryngeal nerve (RLN) is prone to get compressed or damaged, leading to vocal cord palsy, due to pathologies or surgeries of the structures closely surrounding this nerve in the thorax, including the esophagus, aortic arch, pulmonary trunk, and ligamentum arteriosum. We wanted to provide a data set including nerve diameter, its distance from the esophagus, measurements of the pulmonary artery, aorta, and ligamentum arteriosum in close proximity of the nerve in a healthy population to avoid its damage during surgery and predict its chances of compression during the diseased condition. We measured the left RLN and the surrounding structures in 39 well-embalmed cadavers. We compared the values among the male and female cadavers. We found that the mean diameter of the left RLN was $1.75 \mathrm{~mm}$, the mean distance of the nerve from esophagus was $9.88 \mathrm{~mm}$, the mean diameters of the aortic arch and pulmonary artery just distal to the attachment of the ligamentum arteriosum were 26.14 and $19.93 \mathrm{~mm}$, respectively, and the length and width of ligamentum arteriosum were 15.89 and $2.79 \mathrm{~mm}$, respectively. No clinically significant differences were found between male and female parameters. This set of values might be useful while investigating the cause of vocal cord palsies or during surgeries in close proximity to left RLN to avoid its damage.

Received 04/14/2019

Review began 04/20/2019

Review ended 05/31/2019

Published 06/04/2019

(c) Copyright 2019

Ghosh et al. This is an open access article distributed under the terms of the Creative Commons Attribution License CC-BY 3.0., which permits unrestricted use, distribution, and reproduction in any medium, provided the original author and source are credited.
Categories: Anatomy

Keywords: left recurrent laryngeal nerve, aortic arch diameter, pulmonary artery diameter, ligamentum arteriosum, vocal cord palsy

\section{Introduction}

The left recurrent laryngeal nerve (RLN), a branch of the left vagus nerve, passes underneath the aortic arch in the thorax, hooking beneath the ligamentum arteriosum, the fibrous ligament between the aortic arch, and pulmonary artery. Compression of this nerve due to any thoracic pathology or damage during surgical interventions in the thorax may lead to vocal cord palsies manifested by hoarseness in patients. The common thoracic pathologies leading to left RLN palsy include (but are not limited to) the following: patent ductus arteriosus in adults and various cardiac diseases, including mitral stenosis, left ventricular failure, coronary artery disease, pulmonary arterial hypertension, aortic aneurysm, aortic lymph node enlargement in silicosis, and bronchogenic carcinoma involving the left upper lobe of the lung [1-7]. Previous

\section{How to cite this article}

Ghosh A, Chaudhury S (June 04, 2019) Cadaveric Measurements of the Left Recurrent Laryngeal Nerve, Ligamentum Arteriosum, Aortic Arch, and Pulmonary Artery in the Thorax with Clinical Implications and Comparison Between Two Sexes in the American Population. Cureus 11(6): e4828. DOI 
researchers hypothesized that pulmonary arterial dilatation secondary to a wide range of cardiac disorders could be regarded as the single main factor directly responsible for left RLN palsy [1]. Again, the left RLN is considered to be at risk during esophageal resection surgeries, nodal dissection in lung cancer surgeries, and surgical closure of the patent ductus arteriosus in infants [1, 8-11]. Previous researchers tried to find an association between the RLN diameter and chances of injury during surgery [12]. Very limited literature is available providing the relation between the esophagus and the left RLN, as well as the normal diameters of the pulmonary artery and aorta in relation to the left RLN. If we can establish a data set regarding the safe distance of left recurrent laryngeal nerve from the esophagus, the usual range of diameters of this nerve and measurement of ligamentum arteriosum in healthy individuals that might be useful to prevent the inadvertent damage of this nerve during surgical procedures. Again, if a dataset having the usual diameters of pulmonary artery and aorta in healthy adults at close proximity of left RLN can be established, it could predict some disease processes at the beginning (with increased diameters) and predict the chances of compression of left RLN as well. A separate data set for the healthy male and female population might be more useful. The aim of this study is to measure the width of the left RLN in the thorax, the distance of the left RLN from the esophagus, and the diameter of the aorta and left pulmonary artery at the level of the ligamentum arteriosum and compare the values between males and females. In addition, we measured the length and width of the ligamentum arteriosum.

\section{Materials And Methods}

This dissection-based, cross-sectional observational study was conducted at the Department of Anatomy, Medical University of the Americas, Saint Kitts and Nevis, over a period of two years. A total of 42 well-embalmed cadavers, which were available within the two year time period and were free from evident structural cardiovascular pathology, were examined for the study (20 males, 22 females). The ages of the cadavers ranged between 64 - 85 years, the majority were Caucasoid from the USA and no detailed medical history was available. The cadavers were used by medical students for gross anatomy dissection initially, so the thoracic cavities were already exposed using a standardized dissection technique. The cadavers with an intact recurrent laryngeal nerve, aorta, pulmonary trunk, ligamentum arteriosum, and esophagus were utilized for this research. The cadavers with considerable damage to the aforementioned structures were excluded from the study. A total of three cadavers were excluded because of previous damage to either the vagus nerve or pulmonary artery, so a total of 39 cadavers were finally included (19 males, 20 females) and measured in this study. The connective tissues covering the vagus and RLN were cleaned carefully to clearly expose the left RLN in the thorax, and the connective tissue around the aortic arch and pulmonary artery were also cleaned. The ligamentum arteriosum was exposed and secured with fine dissection. The esophagus was dissected underneath the aortic arch. The relation of the left vagus nerve with the three principal branches of the aortic arch (i.e., left subclavian, left common carotid, and brachiocephalic trunk) was noted. The width of the left RLN was measured at its origin from the vagus nerve at the lower border of the aortic arch (Figure 1). 


\section{Cureus}

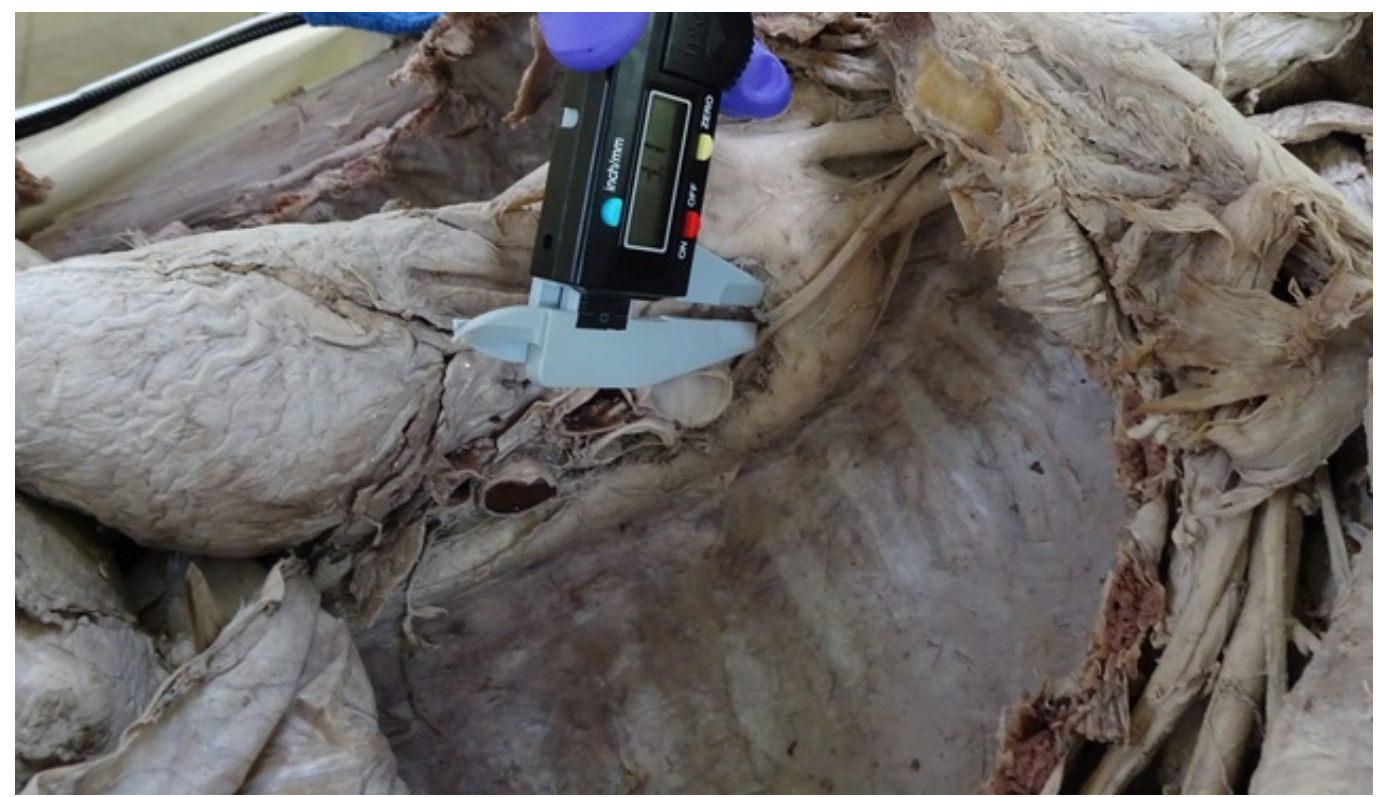

FIGURE 1: Showing the measurement of the left recurrent laryngeal nerve at its origin from the vagus nerve

The angulation between the left vagus nerve and left RLN was measured by a goniometer. The vertical distance between the left RLN and the esophagus was measured at the level of the aortic arch (Figure 2).

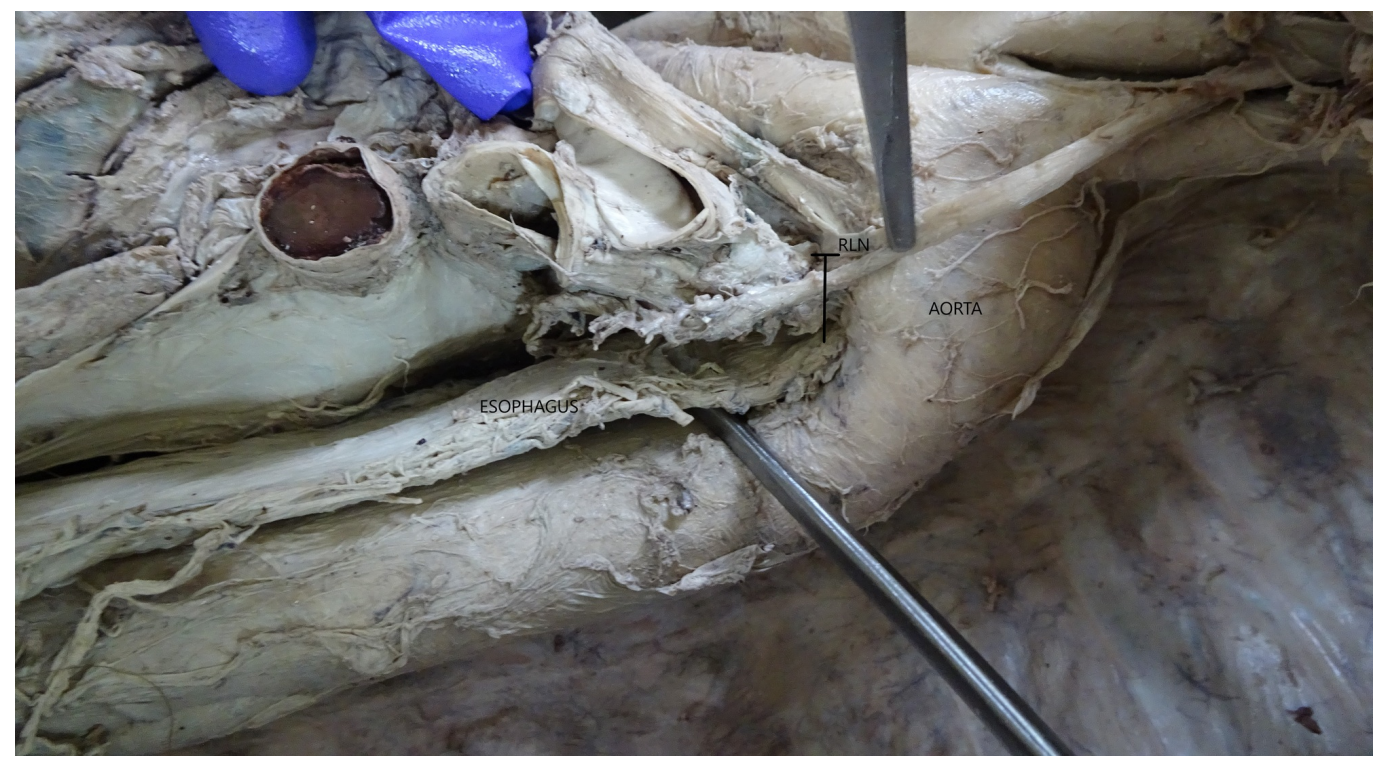

FIGURE 2: Showing the vertical relation between the left recurrent laryngeal nerve (RLN) and esophagus (structure with probe underneath)

The diameter of the aortic arch distal to its attachment to the ligamentum arteriosum was recorded (Figure 3). 


\section{Cureus}

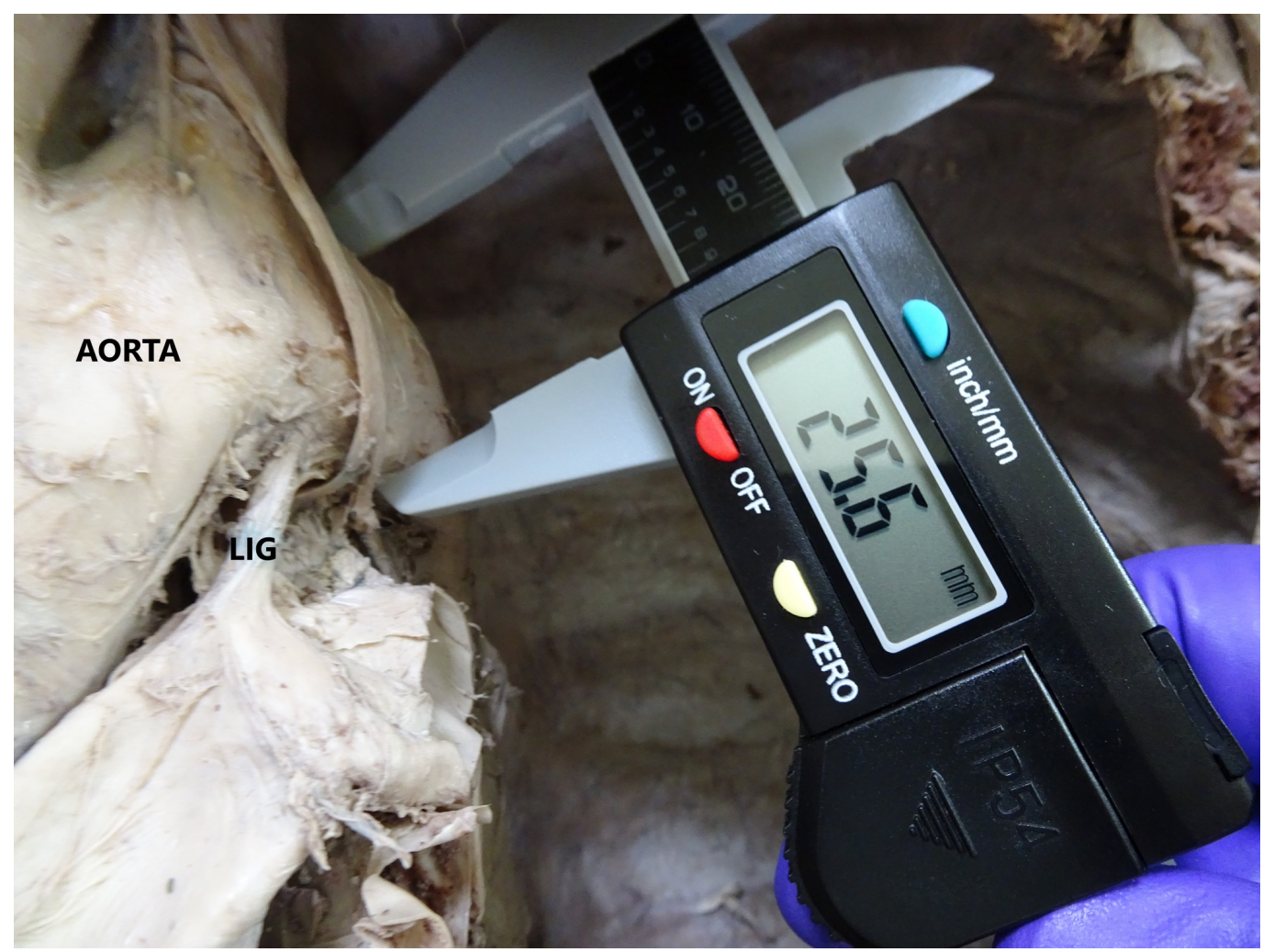

FIGURE 3: Showing the measurement of the diameter of the aortic arch distal to the ligamentum arteriosum (LIG) and vagus nerve

The diameter of the pulmonary artery was measured proximal to its attachment to the ligamentum arteriosum (Figure 4). 


\section{Cureus}

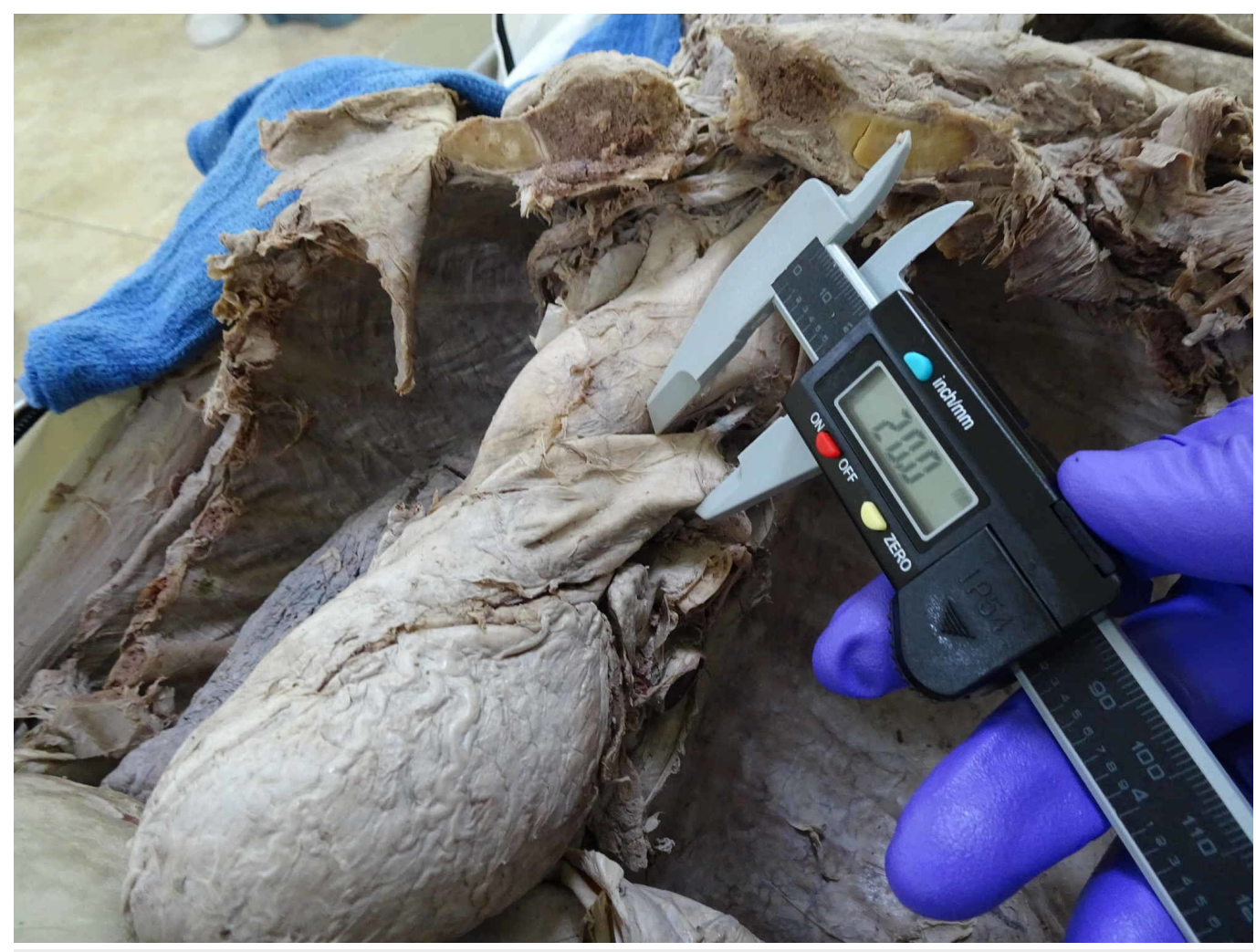

FIGURE 4: Showing the measurement of the pulmonary artery proximal to the attachment of the ligamentum arteriosum

The length of the ligamentum arteriosum was measured between its points of attachments from the undersurface of the aortic arch to the pulmonary artery, and the width of the ligamentum arteriosum was measured roughly at its midpoint (Figure 5). 


\section{Cureus}

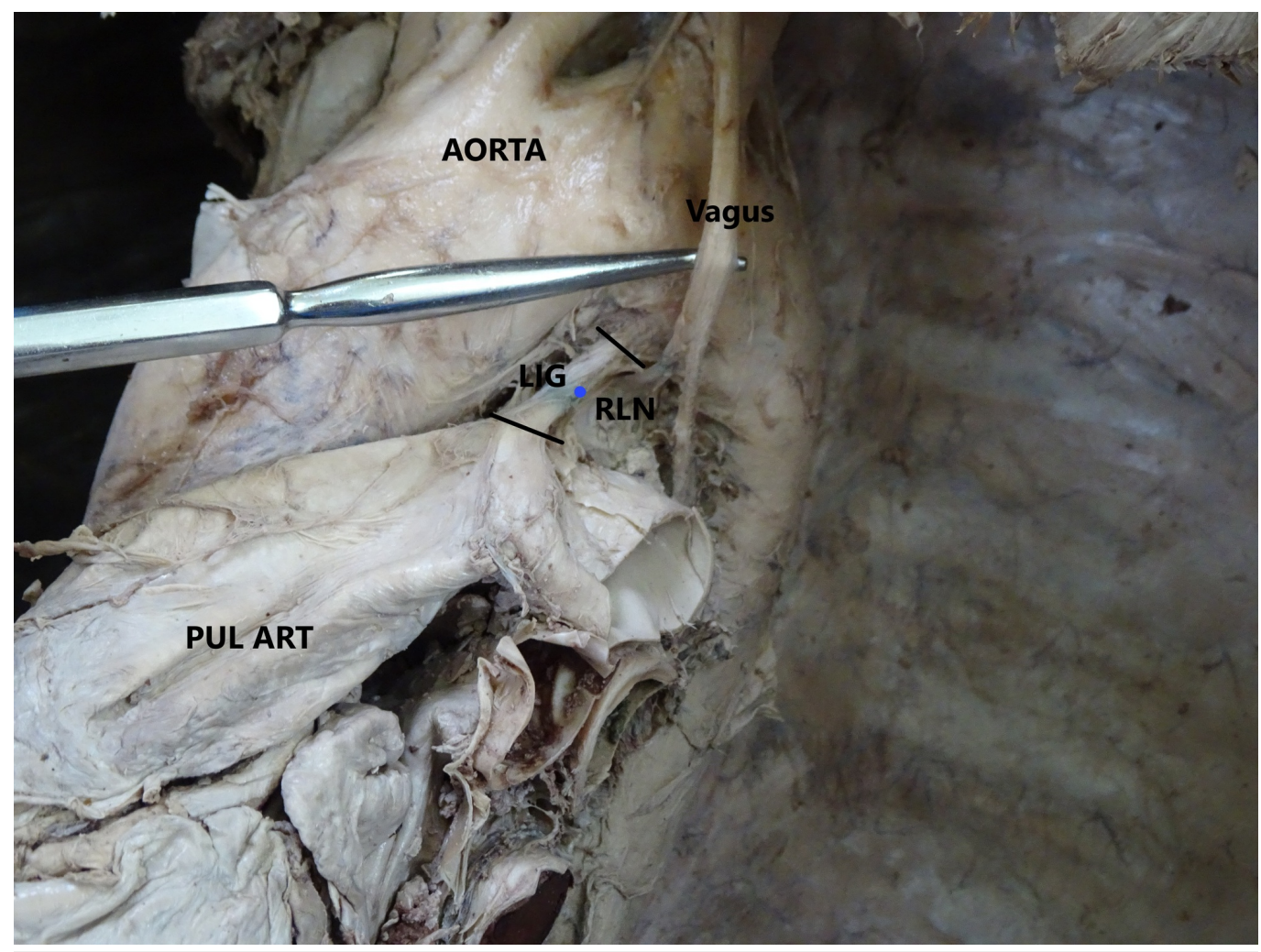

\section{FIGURE 5: Showing the measurement of the ligamentum arteriosum}

LIG: ligamentum arteriosum; PUL ART: pulmonary artery; RLN: recurrent laryngeal nerve

All measurements were done by digital calipers. All the measurements were recorded and photographs were taken. The data analysis (calculation of mean and standard deviation) was done using Microsoft ${ }^{\circledR}$ Excel software (2013) (Microsoft ${ }^{\circledR}$ Corp., Redmond, WA) and p-values were elicited using t-test by an online p-value calculator [13].

\section{Results}

In this study, 39 cadavers (19 males, 20 females) with an intact left vagus nerve, left RLN, and other structures under investigation were included and utilized for the measurements and data analysis. The left RLN made an angle of 5 to 7 degrees with the vagus nerve at its origin. The left RLN hooked underneath the aorta lying lateral to the ligamentum arteriosum in all cases and then coursed along the tracheoesophageal groove towards the larynx. It was seen lying 9.5 to $10.5 \mathrm{~mm}$ superficial to the esophagus in the superior mediastinum. The length of the ligamentum arteriosum varied across the cadavers. The data related to various parameters have been provided in Table 1 . 


\section{Cureus}

\begin{tabular}{|c|c|c|}
\hline Parameters $(\mathrm{mm})$ & Mean $(n=39)$ & SD \\
\hline Width of the RLN & 1.75 & 0.41 \\
\hline Distance of the RLN from the esophagus & 9.88 & 0.31 \\
\hline Diameter of the aorta & 26.14 & 2.43 \\
\hline Diameter of the pulmonary artery & 19.93 & 1.08 \\
\hline Ligamentum arteriosum - length, width & $15.89,2.79$ & $4.64,0.64$ \\
\hline
\end{tabular}

\section{TABLE 1: Showing the Average Values of Various Parameters in All Cadavers}

RLN: recurrent laryngeal nerve; SD: standard deviation

No obvious difference was noted in the parameters among male and female cadavers (Tables $2-3)$. In addition, the left vagus nerve was seen to pass over the left subclavian artery in $80 \%$ of the cadavers. In 15\%, the nerve passed along the medial border of the left subclavian artery, and in $5 \%$ of the cases, the vagus nerve crossed midway between the left common carotid and left subclavian artery while entering the thorax.

\begin{tabular}{|c|c|c|c|c|c|c|c|}
\hline \multirow{2}{*}{ Parameters (mm) } & \multicolumn{3}{|c|}{ Male $(n=19)$} & \multicolumn{3}{|c|}{ Female $(n=20)$} & \multirow[t]{2}{*}{ Observation } \\
\hline & Mean & SD & Range & Mean & SD & Range & \\
\hline Width of the RLN & 1.85 & 0.38 & $1.5-3$ & 1.65 & 0.43 & $1.2-3$ & $\begin{array}{l}P=0.08 \text { Not } \\
\text { clinically significant }\end{array}$ \\
\hline $\begin{array}{l}\text { Distance of RLN from the } \\
\text { esophagus }\end{array}$ & 9.87 & 0.3 & $\begin{array}{l}9.5- \\
10.5\end{array}$ & 9.9 & 0.33 & $\begin{array}{l}9.5- \\
10.5\end{array}$ & $\begin{array}{l}P=0.77 \text { Not } \\
\text { clinically significant }\end{array}$ \\
\hline Diameter of the aorta & 26.78 & 2.35 & $\begin{array}{l}21.7- \\
30\end{array}$ & 25.5 & 2.5 & $\begin{array}{l}20.4- \\
28.5\end{array}$ & $\begin{array}{l}P=0.1 \text { Not } \\
\text { clinically significant }\end{array}$ \\
\hline $\begin{array}{l}\text { Diameter of the pulmonary } \\
\text { artery }\end{array}$ & 19.71 & 1.15 & $\begin{array}{l}17- \\
21\end{array}$ & 20.15 & 1.0 & $\begin{array}{l}19- \\
21.6\end{array}$ & $\begin{array}{l}P=0.21 \text { Not } \\
\text { clinically significant }\end{array}$ \\
\hline
\end{tabular}

\section{TABLE 2: Showing the Comparison Between Male and Female Values}

RLN: recurrent laryngeal nerve; SD: standard deviation 


\section{Cureus}

\begin{tabular}{|c|c|c|c|c|c|c|c|}
\hline \multirow{2}{*}{ Ligamentum arteriosum (mm) } & \multicolumn{3}{|l|}{ Male } & \multicolumn{3}{|c|}{ Female } & \multirow{2}{*}{ Observation } \\
\hline & Mean & SD & Range & Mean & SD & Range & \\
\hline Length & 16.83 & 4.62 & $7-27$ & 14.95 & 4.65 & $6-25$ & $P=0.21$ Not clinically significant \\
\hline Width & 2.98 & 0.75 & $2.2-4.5$ & 2.59 & 0.52 & $2-3.5$ & $P=0.07$ Not clinically significant \\
\hline
\end{tabular}

\section{TABLE 3: Showing the Measurement Values of Ligamentum Arteriosum in Male and}

Female Cadavers

SD: standard deviation

\section{Discussion}

The current study provides a set of measurement values, including the left RLN diameter, the diameter of the aorta and pulmonary trunk at the level of attachment to the ligamentum arteriosum, the length and width of the ligamentum arteriosum, and the vertical distance of the left RLN trunk from the esophagus in the superior mediastinum.

In this study, we found the mean diameter of the left RLN was $1.75 \mathrm{~mm}( \pm 0.41)$ in cadavers, while in a study by Saito et al., the median size of this nerve was found to be $1.51 \mathrm{~mm}$ in living patients [12]. The difference in study methodology (cadaveric measurements in the present study and digital video recording, while surgical procedure in living esophageal cancer patients in the study by Saito et al.), way of measurement (digital caliper measurement versus calculating ratio between scissor size and nerve size), difference in ethnicity, and the size of the study population could be some possible causes of this reported difference. Vocal cord palsies are quite common in esophageal resection surgeries [8, 14]. According to Saito et al. [12], the width of the left RLN can be regarded as a predictor of post-surgical vocal cord palsies in esophageal resections. They found that a thin left RLN (having a diameter less than $1.5 \mathrm{~mm}$ ) should be regarded as a high-risk factor in these surgeries. Amer suggested that a complete exposure of the left RLN during nodal dissection surgeries might the best possible way to avoid its damage [9]. The current study found the average vertical distance of the left RLN from the esophagus was $9.88 \mathrm{~mm}( \pm 0.31)$ when the nerve returns back towards the larynx along the tracheoesophageal groove. Edwards and McCullagh reported that in $95 \%$ of the cases the distance between the RLN and the esophagus was less than $1 \mathrm{~cm}$, which corroborates with our findings [8].

In the current study, we found the average diameter of the aortic arch was $26.14 \pm 2.43 \mathrm{~mm}$ just distal to the attachment of the ligamentum arteriosum. An aortic aneurysm may lead to vocal cord palsy by compressing the left RLN; again, left RLN damage and vocal cord palsy may set in as a sequela of thoracic aortic aneurysm repair surgery [5]. In a study by Lee et al., the average diameter of the ascending aorta recorded by thoracic imaging was $30.7 \mathrm{~mm}$ and $32.8 \mathrm{~mm}$ in female and male subjects, respectively [15]. They concluded factors, including sex, systemic diseases, and lifestyle, do influence the aortic diameter. In our study, the diameters of the aortic arch in male and female cadavers were 26.78 and $25.5 \mathrm{~mm}$, respectively. Although male cadavers showed relatively higher values in most of the parameters, no clinically significant difference was observed (Figure 6). Selecting different parts of the thoracic aorta for measurements could be responsible for the discrepancy in the findings among the current study and the study by Lee et al. In the present study, the average diameter of pulmonary artery just 


\section{Cureus}

distal to the attachment of the ligamentum arteriosum was found to be $19.9 \pm 1.08 \mathrm{~mm}$. Lee et al. reported the average diameter of the main pulmonary artery was $26 \pm 3.4$ and $27 \pm 3.4 \mathrm{~mm}$, respectively, in female and male participants [15]. The difference of the findings could be contributed by (but not limited to) the following: different anatomical sites of measurements and post-embalming tissue shrinkage in cadavers [16]. Kuryama et al. suggested that computed tomography (CT) scan measurements of the pulmonary arterial diameter could be useful in detecting pulmonary arterial hypertension (HTN) and could be utilized to estimate the pulmonary arterial pressure [17]. Lange et al. suggested that pulmonary arterial diameter measured by thoracic CT could even predict borderline pulmonary hypertension and plan early diagnosis of underlying pathologies [18].

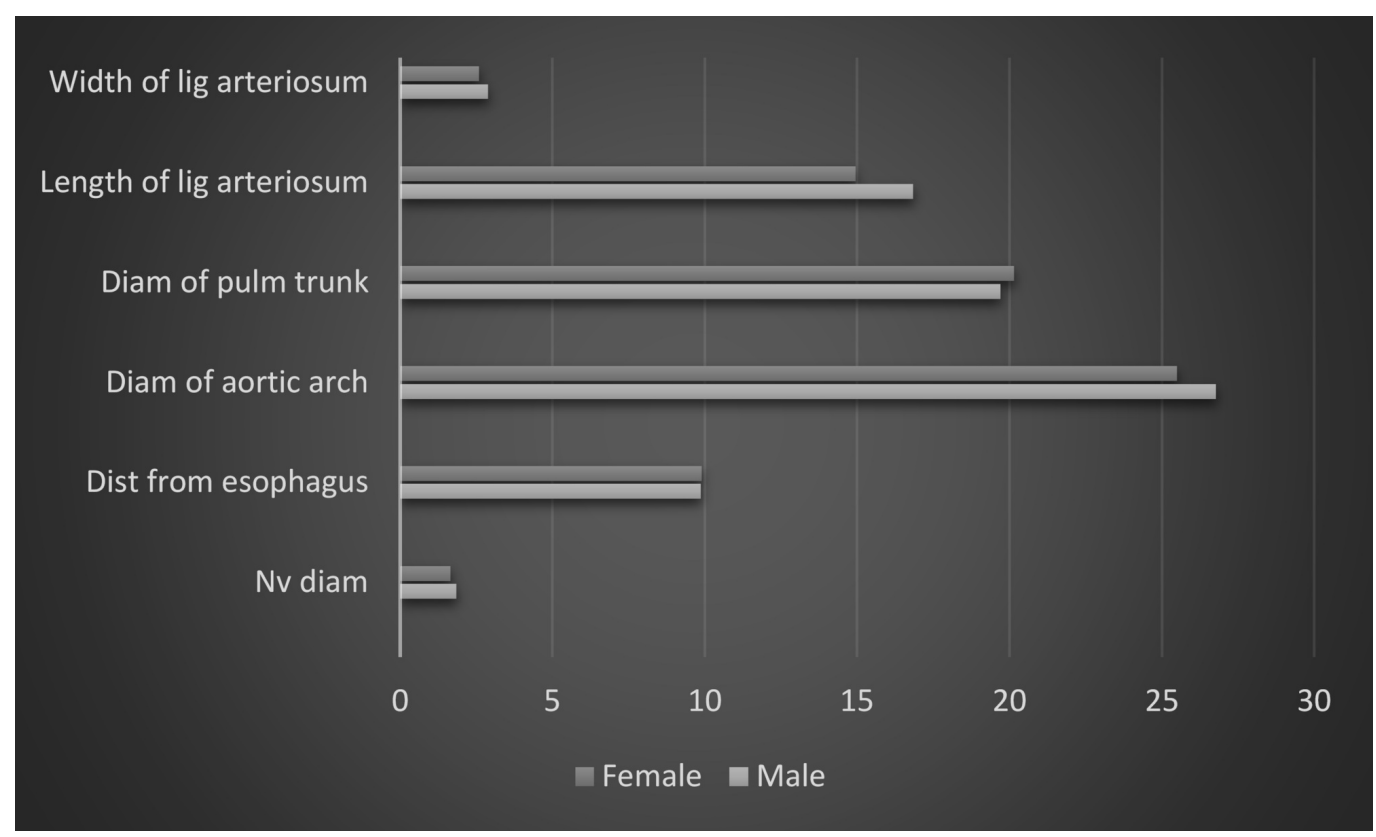

\section{FIGURE 6: Showing a comparison between male and female} values

$\mathrm{x}$-axis represents measurements in millimeters

Diam: diameter; Dist: distance; lig: ligamentum; Nv: recurrent laryngeal nerve; Pulm: pulmonary

In the present study, the left RLN was found lateral to the ligamentum arteriosum in all cases. However, previous studies reported the location of ligamentum arteriosum might not be constant, and in rare cases, it could be located medial to the ligamentum arteriosum due to variation in embryonic development [19-20]. In our study, the average length and width of the ligamentum arteriosum were $15.89 \pm 4.64$ and $2.69 \pm 0.64 \mathrm{~mm}$, respectively. In a study by Keet et al., the length and width of the ligament were reported as $14.65 \pm 7.33 \mathrm{~mm}$ and $2.86 \pm 0.87 \mathrm{~mm}$, respectively, which are very close to our findings. The length of the ligamentum varied from 6 to $27 \mathrm{~mm}$ across our study population, whereas Keet et al. reported the range as 3.48 - 31.48 $\mathrm{mm}[20]$.

The major limitation of this study is the small sample size and inability to know if any of these persons suffered from left RLN palsies and cardiac disorders. The second limitation is possible embalming-related tissue shrinkage and alteration of the venous size which might limit the clinical comparability of the recorded data. Future studies should be performed in a larger population and measurements should be compared between the normal population and the 
population with vocal cord palsy. A study on the pediatric population would be useful to provide guidelines for pediatric surgeries.

\section{Conclusions}

In conclusion, we found the mean diameter of the left RLN was $1.75 \mathrm{~mm}$, the mean distance of the nerve from the esophagus was $9.88 \mathrm{~mm}$. The mean diameter of the aortic arch and the pulmonary artery just distal to the attachment of ligamentum arteriosum was 26.14 and 19.93 $\mathrm{mm}$, respectively. The length and width of the ligamentum arteriosum were 15.89 and $2.79 \mathrm{~mm}$, respectively. The range of measurements involving the recurrent laryngeal nerve, esophagus, aortic arch, pulmonary trunk, and ligamentum arteriosum might be useful for clinicians when investigating the underlying causes of left RLN palsy or while performing surgical procedures in close proximity to the left RLN in order to avoid damage to this nerve.

\section{Additional Information}

\section{Disclosures}

Human subjects: Consent was obtained by all participants in this study. Animal subjects: All authors have confirmed that this study did not involve animal subjects or tissue. Conflicts of interest: In compliance with the ICMJE uniform disclosure form, all authors declare the following: Payment/services info: All authors have declared that no financial support was received from any organization for the submitted work. Financial relationships: All authors have declared that they have no financial relationships at present or within the previous three years with any organizations that might have an interest in the submitted work. Other relationships: All authors have declared that there are no other relationships or activities that could appear to have influenced the submitted work.

\section{Acknowledgements}

We sincerely thank all those who donated their bodies for anatomical study and research without whom this study would not be possible.

\section{References}

1. Nakahira M, Nakatani H, Takeda T: Left vocal cord paralysis associated with long-standing patent ductus arteriosus. AJNR Am J Neuroradiol. 2001, 22:759-61.

2. Nakao M, Sawayama T, Samukawa M, Mitake H, Nezuo S, Fuseno H, Hasegawa K: Left recurrent laryngeal nerve palsy associated with primary pulmonary hypertension and patent ductus arteriosus. J Am Coll Cardiol. 1985, 5:788-92. 10.1016/S0735-1097(85)80413-7

3. Stocker HH, Enterline HT: Cardio-vocal syndrome: laryngeal paralysis in intrinsic heart disease. Am Heart J. 1958, 56:51-59. 10.1016/0002-8703(58)90158-3

4. Thompson JL Jr, Kistin AD: Hoarseness in heart disease. Ann Intern Med. 1948, 29:259-73. 10.7326/0003-4819-29-2-259

5. Teixido MT, Leonetti JP: Recurrent laryngeal nerve paralysis associated with thoracic aortic aneurysm. Otolaryngol Head Neck Surg. 1990, 102:140-44. 10.1177/019459989010200207

6. Lardinois D, Gugger M, Balmer MC, Ris HB: Left recurrent laryngeal nerve palsy associated with silicosis. Eur Respir J. 1999, 14:720-22. 10.1034/j.1399-3003.1999.14c37.x

7. Moore KL, Dalley AF, Agur AMR: Clinically Oriented Anatomy, 8th Ed. Moore KL, Dalley AF, Agur AMR (ed): Wolters Kluwer, Philadelphia; 2018.

8. McCullagh M, Edwards MH: How vulnerable is the recurrent laryngeal nerve in esophageal surgery?. Diseases of the Esophagus. Siewert JR, Hölscher AH (ed): Springer, Berlin, Heidelberg; 1988. 443-46. 10.1007/978-3-642-86432-2_99

9. Amer K: Anatomy of the thoracic recurrent laryngeal nerves from a surgeon's perspective . Anat Physiol. 2017, 7:272. 10.4172/2161-0940.1000272

10. Malcolm WF, Hornik C, Evans A, Smith PB, Cotten CM: Vocal fold paralysis following surgical 
ductal closure in extremely low birth weight infants: a case series of feeding and respiratory complications. J Perinatol. 2008, 28:782-85. 10.1038/jp.2008.109

11. Engeseth MS, Olsen NR, Maeland S, Halvorsen T, Goode A, Røksund OD: Left vocal cord paralysis after patent ductus arteriosus ligation: a systematic review. Paediatr Respir Rev. 2018, 27:74-85. 10.1016/j.prrv.2017.11.001

12. Saito Y, Takeuchi H, Fukuda K, et al.: Size of recurrent laryngeal nerve as a new risk factor for postoperative vocal cord paralysis. Dis Esophagus. 2018, 31:dox162. 10.1093/dote/dox162

13. MEDCALC Easy-to-use Statistical Software. (2019). Accessed: March 23, 2019: http://www.medcalc.org/calc/comparison_of_means.php.

14. Yamada M, Hirano M, Ohkubo H: Recurrent laryngeal nerve paralysis. A 10 year review of 564 patients. Aurus Nasus Larynx. 1983, 10:S1-15. 10.1016/S0385-8146(83)80001-7

15. Lee SH, Kim JY, Lee HJ, et al.: Comparison of CT-determined pulmonary artery diameter, aortic diameter, and their ratio in healthy and diverse clinical conditions. PLoS One. 2015, 10:e0126646. 10.1371/journal.pone.0126646

16. Jonmarker S, Valdman A, Lindberg A, Hellström M, Egevad L: Tissue shrinkage after fixation with formalin injection of prostatectomy specimens. Virchows Archiv. 2006, 449:297-301. 10.1007\%2Fs00428-006-0259-5

17. Kuriyama K, Gamsu G, Stern RG, Cann CE, Herfkens RJ, Brundage BH: CT-determined pulmonary artery diameters in predicting pulmonary hypertension. Invest Radiol. 1984, 19:1622.

18. Lange TJ, Dornia C, Stiefel J, Stroszczynski C, Arzt M, Pfeifer M, Hamer OW: Increased pulmonary artery diameter on chest computed tomography can predict borderline pulmonary hypertension. Pulm Circ. 2013, 3:363-68. 10.4103/2045-8932.113175

19. Khaki AA, Tubbs RS, Shoja MM, Zarrintan S: An unusual course of the left recurrent laryngeal nerve. Clin Anat. 2007, 20:344-46. 10.1002/ca.20341

20. Keet K, Gunston G, Alexander R: Variation in the anatomy of the ligamentum arteriosum in a South African sample. Eur J Anat. 2018, 22:119-25. 